\title{
Whisker Formation on SAC305 Soldered Assemblies
}

\author{
S. MESCHTER, ${ }^{1,4}$ P. SNUGOVSKY,${ }^{2}$ Z. BAGHERI ${ }^{2}$ E. KOSIBA, ${ }^{2}$ \\ M. ROMANSKY, ${ }^{2}$ J. KENNEDY, ${ }^{2}$ L. SNUGOVSKY, ${ }^{3}$ and D. PEROVIC ${ }^{3}$ \\ 1.-BAE Systems, Endicott, NY 13760, USA. 2.-Celestica, Toronto, ON M3C-1V7, Canada \\ 3.-University of Toronto, Toronto, ON M5S-2J7, Canada. 4.-e-mail: stephan.j.meschter@ \\ baesystems.com
}

This article describes the results of a whisker formation study on SAC305 assemblies, evaluating the effects of lead-frame materials and cleanliness in different environments: low-stress simulated power cycling $\left(50-85^{\circ} \mathrm{C}\right.$ thermal cycling), thermal shock $\left(-55^{\circ} \mathrm{C}\right.$ to $\left.85^{\circ} \mathrm{C}\right)$, and high temperature/high humidity $\left(85^{\circ} \mathrm{C} / 85 \% \mathrm{RH}\right)$. Cleaned and contaminated small outline transistors, large leaded quad flat packs (QFP), plastic leaded chip carrier packages, and solder balls with and without rare earth elements (REE) were soldered to custom designed test boards with Sn3Ag0.5Cu (SAC305) solder. After assembly, all the boards were cleaned, and half of them were recontaminated $\left(1.56 \mu \mathrm{g} / \mathrm{cm}^{2}\right.$ $\mathrm{Cl}^{-}$). Whisker length, diameter, and density were measured. Detailed metallurgical analysis on components before assembly and on solder joints before and after testing was performed. It was found that whiskers grow from solder joint fillets, where the thickness is less than $25 \mu \mathrm{m}$, unless REE was present. The influence of lead-frame and solder ball material, microstructure, cleanliness, and environment on whisker characteristics is discussed. This article provides detailed metallurgical observations and select whisker length data obtained during this multiyear testing program.

\section{INTRODUCTION}

After the European Union RoHS directive deadline was enacted in July 2006, the electronics industry began a transition to manufacturing with $\mathrm{Sn}-\mathrm{Ag}-\mathrm{Cu}$ (SAC) near-eutectic alloys to avoid the use of $\mathrm{Pb}$-based solders. This change has had little impact on most commercial consumer products because of the limited life requirements and relatively benign use environments. However, lead-free implementation for the aerospace and defense industry requirements, which includes long service lifetimes, rugged operating environments, and high consequences of failure, requires additional evaluation to assure safe systems operation.

The new $\mathrm{Pb}$-free and high $\mathrm{Sn}($ about 96\%) alloys may be susceptible to spontaneous growths of filament-like tin structures called tin whiskers. $\mathrm{Pb}$ is well known as an effective suppressant of whisker formation. Without $\mathrm{Pb}$, the military, aerospace, and other high-reliability industries have experienced increased risks of system failure due to tin whiskers that cause electrical short circuits, impact highfrequency circuits, and create loose debris. ${ }^{1,2}$ The majority of recent tin whisker research has concentrated on coupons or components with an emphasis on the Sn plating composition, thickness, grain size, grain orientations, and $\mathrm{Ni}$ underlayer. ${ }^{2-12}$ These studies produced a great deal of knowledge; however, they do not consider the very real situation in which components are assembled on circuit boards using $\mathrm{Pb}$-free solder pastes. Recent observations have demonstrated the ability of $\mathrm{Pb}$-free solder joints to grow whiskers. ${ }^{13,14}$ One challenge accompanying real electronic systems is the interplay among the component design and materials, manufacturing process, and service environments that contribute directly or conspire with one another to exacerbate whisker growth.

This article is focused on highlights from the Whisker Testing and Modeling project ${ }^{15}$ funded by the U.S. Strategic Environmental Research Program. The objective of this project is to perform systematic tin whisker testing and Monte Carlo risk modeling on lead-free electronic assemblies in order to improve the reliability of military electronic systems. The observations described in this article are based on an extremely large set of data; 129724 
whiskers were counted and 10985 whiskers were measured.

\section{EXPERIMENTAL}

\section{Approach}

The experimental portion of this study was designed to study the role of selected manufacturing process variables in the growth of tin whiskers under certain isothermal and thermal cycling environments. The main assembly variables include package type and lead/ball materials as well as component and assembly cleanliness. Electronic components were attached to printed circuit boards to form a functional printed circuit assembly. Component leads were electrically and mechanically fixed to the board $\mathrm{Cu}$ pads with molten SAC305 solder. During reflow, the solder starts melting at $217^{\circ} \mathrm{C}$. The solder then wicks up the leads and dissolves the electroplated Sn part. The rest of the electroplated Sn melts at $232^{\circ} \mathrm{C}$ and continues mixing with the molten phase. During cooling, this mixture solidifies. The temperature range of the solder joints across the board varies with the minimum acceptable temperature of $232^{\circ} \mathrm{C}$ and the maximum of $255^{\circ} \mathrm{C}$. Therefore, after $\mathrm{Pb}$-free reflow there is no original electroplated Sn coverage of the component leads. The modified component tin or tin alloy coverage after assembly might be thicker or thinner than electroplated Sn before assembly, and it has an elemental composition closer to the original SAC solder or pure Sn depending on the component type (length of the leads), location, and reflow parameter and solidified microstructure.

\section{Test Vehicle}

Three custom boards were designed to evaluate the key piece parts of interest. The small outline transistor (SOT) board has three, five, and six leaded SOT parts with C194 Cu alloy and alloy-42 alloy leads. The quad flat pack (QFP) board has C7025 Cu alloy high pin count QFPs with two lead pitches and a C151 Cu alloy plastic leaded chip carrier (PLCC). The ball grid array (BGA) board contains solder alloy balls that evaluate whisker growth on Ce rare earth element (REE) additions to SAC. The test vehicles for this study are small boards $6 \mathrm{~cm} \times 6 \mathrm{~cm}$ in size processed together 12-up on a panel (Fig. 1). The boards were separated after surface-mount soldering, inspected, and then subjected to the environments. The parts were distributed across three different board designs, designated as the SOT board, the QFP board, and the BGA board. The board was found to be well suited for inspection by scanning electron microscopy (SEM) because the board fit easily into the SEM's sample chamber. The placement area was limited to $5 \mathrm{~cm} \times 5 \mathrm{~cm}$ to ensure all leads of interest were contained in a region that could be viewed by the SEM. The boards are $0.24 \mathrm{~cm}$ thick and are a double-layer design

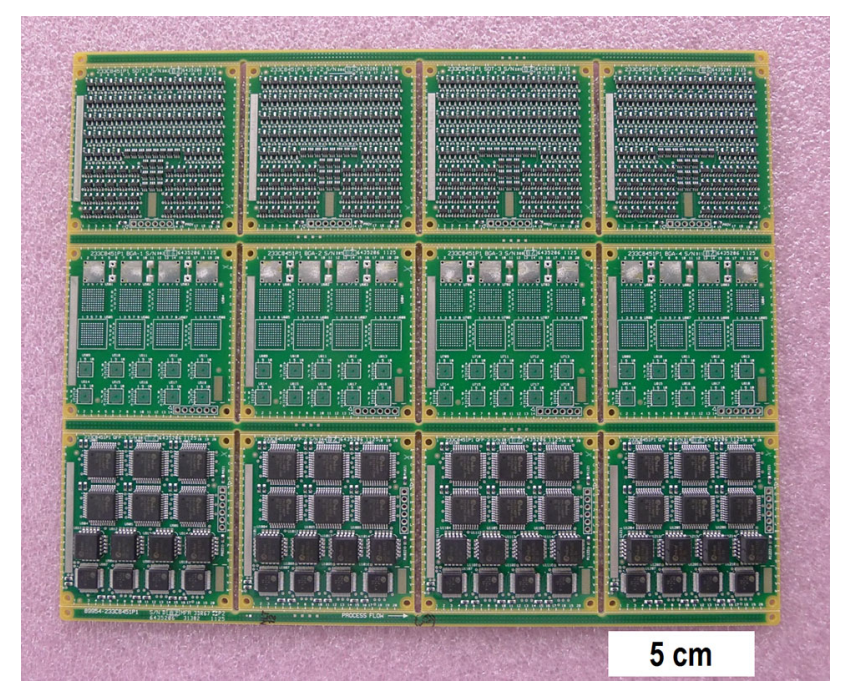

Fig. 1. Test vehicle assembly soldering panel.

manufactured in accordance with IPC-6012 Class 3, Type 2 with high-temperature woven $\mathrm{E}$ glass epoxy laminate (IPC-4101/126), Cu foil (IPC-4562/3 Type E Grade 3 [HTE]), solder mask over bare $\mathrm{Cu}$ (IPCSM-840 Class H liquid photoimageable), with immersion tin over $\mathrm{Cu}$ finish (IPC-6012, Type IT) (IPC Association Connecting Electronics Industries, Bannockburn, IL).

The SOT board has 64 alloy-42 lead material SOT3 Fairchild 2N7002 parts, 40 C194 lead material SOT5 Fairchild NC7S08M5X parts, and 17 alloy-42 lead material SOT6 Diodes Inc. 2N7002DW7-F parts (Diodes Inc., Plano, TX). The lead composition for the alloy-42 is $\mathrm{Fe}-42 \mathrm{Ni}$ and the $\mathrm{Cu}$ alloy $\mathrm{C} 194$ is $\mathrm{Cu} 2.1-2.6 \mathrm{Fe}-0.015-0.15 \mathrm{P}-0.05-0.2 \mathrm{Zn}$. The QFP board has the following $\mathrm{Cu}$ alloy lead material (Practical Components Inc., Los Alamitos, CA) and Amkor Technology (Chandler, AZ) parts (Practical Components Inc.,): six C7025 lead material QFP44 A-QFP44-10 mm-0.8-3.2-DC-Sn (0.8-mm pitch) parts, four C151 lead material PLCC20 A-PLCC20TDC-Sn (1.25-mm pitch) parts, and four C7025 lead material QFP64 A-LQFP64-0.7 mm-0.4 mm-2.0DC-Sn (0.4-mm pitch) parts. The lead composition for the $\mathrm{C} 7025$ is $\mathrm{Cu} 2.2-4.2 \mathrm{Ni} 0.25-1.2 \mathrm{Si0} .05-0.3 \mathrm{Mg}$ and for the C151 is Cu0.1Zr. Half of the SOT3, SOT5, QFP44, and QFP64 parts contained some leads with a $5-\mathrm{V}$ bias and the remainder was grounded. The SOT6 and PLCC parts were not connected electrically and are contained in the zero volt bias data presented in this study.

The BGA board contains provisions for two types of BGA components (100 ball 0.8-mm pitch Amkor CABGA and a 97 ball 0.4-mm pitch Amkor CVBGA. In the present evaluation, BGA devices were not soldered to the boards because of the difficulty of inspecting for whiskers under the package; only balls were populated. Two different ball alloys were studied on the land pattern area SAC105 and 
SAC105 with Ce REE added. These were compared with pads printed with SAC305 paste.

\section{Assembly}

Before assembly components were divided into two groups. The first group was cleaned using the method developed in screening experiments. ${ }^{16}$ The samples were cleaned twice to get the level of contamination 10 times below typical acceptable industry level and did not exceed $0.062 \mu \mathrm{g} / \mathrm{cm}^{2}$ $\left(0.4 \mu \mathrm{g} / \mathrm{in}^{2}\right) \mathrm{Cl}$. The second group was contaminated with $\mathrm{NaCl}$ using the method developed earlier. ${ }^{16}$ The piece part level of chlorine contamination $0.465 \mu \mathrm{g} / \mathrm{cm}^{2}\left(3 \mu \mathrm{g} / \mathrm{in}^{2}\right)$ was selected to be within the industry levels encountered (no standards exist).

Both component groups cleaned and intentionally contaminated were assembled using SAC305 solder paste. Assembled boards with clean and contaminated components were divided into two groups each. The first group was cleaned after assembly and the second group was purposely contaminated after assembly. The assembly level of equivalent chlorine contamination was selected to be within the J-STD-001 (IPC Association Connecting Electronics Industries, Bannockburn, IL) industry limits typically used to provide satisfactory electrical function-approximately $\quad 1.56 \mu \mathrm{g} / \mathrm{cm}^{2} \quad\left(10 \mu \mathrm{g} / \mathrm{in}^{2}\right)$ Cl. The contamination levels are designated as: $0-0=$ no part contamination-no board contamination; $0-1=$ no part contamination-board contamination; $1-0=$ part contamination-no board contamination; and $1-1$ = part contamination-board contamination.

For the assembly of the BGA boards, 0.4-mm (0.0157 in) diameter spheres were ordered from a major solder manufacturer. The target concentration was $0.5 \%$ Ce. The ball manufacturer had difficulty attaining this level and it was found to be $<0.01 \%$ Ce. Then, after soldering to the board with SAC305 paste, the Ce concentration was further reduced.

\section{Experimental Environments and Testing}

Four environments were selected to assess whisker growth. There were two isothermal high humidity environments; a long-term low-temperature high humidity (LTHH) and a short-term hightemperature high humidity (HTHH). In addition, there were two thermal cycling conditions used: a simulated power cycling thermal cycle (PCTC) and a thermal shock cycle (TC). In high-humidity conditions, $85^{\circ} \mathrm{C}$ has been shown to promote whisker growth in lead-free solder alloys. ${ }^{12-14}$ The two isothermal high-humidity environments employed were $25^{\circ} \mathrm{C} / 85 \% \mathrm{RH}$ (3 years) and $85^{\circ} \mathrm{C} / 85 \% \mathrm{RH}$ $(4,000 \mathrm{~h})$. The PCTC cycle was $+50^{\circ} \mathrm{C}$ to $85^{\circ} \mathrm{C}$ with 15 -min ramps and dwells in air simulating the conditions in Ref. ${ }^{17}$ that grew whiskers when rework flux contamination was present. The TC cycle was $-55^{\circ} \mathrm{C}$ to $85^{\circ} \mathrm{C}$ with three cycles per hour air-to-air thermal shock as defined in JESD201 Environmental Acceptance Requirements for Tin Whisker Susceptibility of Tin and Tin Alloy Surface Finishes (JEDEC Solid State Technology Association, Arlington, VA) and has representative temperature limits but temperature ramp rates that are much greater than moderate aerospace service conditions. Note that in the PCTC testing, the actual measured chamber temperature was $48-88^{\circ} \mathrm{C}$ and humidity was not controlled, but it was measured to be between $25 \% \mathrm{RH}$ at $88^{\circ} \mathrm{C}$ to $10 \% \mathrm{RH}$ at $48^{\circ} \mathrm{C}$. For the TC cycle, the humidity was not controlled or measured.

\section{Whisker Inspection}

The assemblies were removed for inspection at progressively increasing exposure times. For example, the PCTC samples were first examined after 250 cycles, returned to cycling for an additional 500 cycles and inspected at 750 cycles $(250+500)$, then returned for an additional 1000 cycles and inspected at 1750 cycles $(250+500+1000)$. The industry whisker inspection and measurement standard JESD22A121A Test Method for Measuring Whisker Growth on Tin and Tin Alloy Surface Finishes (JEDEC Solid State Technology Association) developed for part-level whisker measurement was adapted for the assembled parts. The parts were randomly selected for inspection and approximately 50-100 leads were examined for each part condition. The same parts and leads were inspected by the same person for all environments to monitor the whisker growth progression on the leads and minimize operator related inspection variation. Inspections were performed at increasingly longer intervals with the boards being returned to the chamber. The whisker length criterion in JESD22A121A was used to perform the whisker length measurements in the SEM. Whiskers longer than $10 \mu \mathrm{m}$ were measured for all experiments except for the HTHH 4000-h inspection, where only whisker lengths greater than approximately $30-40 \mu \mathrm{m}$ were measured to concentrate limited inspection resources on the longest whiskers. A unique aspect of measuring whiskers on assemblies is that the whisker growth surfaces are nonplanar and the sample must be continually rotated and tilted during the inspection. In the current work, the reported whisker length measurements are conservative. During the length measurement procedure, the SEM inspection azimuth axis was adjusted to be aligned to within approximately $30^{\circ}$ from perpendicular to the whisker. The SEM axis misalignment from the whisker normal results in a potential whisker length underreporting of up to $15 \%$. All whisker lengths and diameters are reported in microns.

The detailed inspection was performed using an SEM. The occurrence of a whisker was counted if it was observable at 100 times magnification in the SEM. There was no differentiation between odd shaped eruptions and whiskers in the occurrence count. For the whisker-length measurements, an SEM magnification higher or lower than that used for inspection may be required, such that the whisker 
being measured approximately fills the field of view at the selected magnification. The numbers of whiskers were recorded along with the amount of surface area that was inspected as well as the region of the lead where the measurements were made. These were the same regions that were used to obtain the whisker length. For selected whiskers, the whisker diameter or thickness was measured by drawing a line perpendicular to the whisker axis. ${ }^{12}$

\section{Metallurgical Analysis}

Sequential whisker cross sectioning was performed on representative whiskers with SEM inspection at various slice depths. A metallurgical evaluation was performed to determine the tin grain morphology, intermetallic (IMC) layer thickness and morphology, and IMC particle distribution at the base of the whisker and in the whisker itself. Optical and SEM images and EDX elemental spectrum were used to record findings similar to the results published by authors in 2008 and $2012 .^{16,17}$

\section{RESULTS AND DISCUSSION}

\section{Characterization of Components Before and After Assembly}

SOT and QFP board parts were analyzed before assembly in the as-received condition, after cleaning and after intentional contamination. The assembled boards were cross sectioned to study the solder microstructure, component coverage, IMC characteristics, and contamination distribution.

\section{As-Received Parts}

There were no significant anomalies in the plating of the part leads relating to solderability. Some defects important for whiskering that are not commonly reported (Fig. 2) such as exposed base metal, thin plating from lead forming, voids, roughness, and deep surface grooves and some ionic contamination such as $\mathrm{Cl}, \mathrm{S}, \mathrm{Si}, \mathrm{Na}$, and $\mathrm{Br}$ were detected. The QFP44, QFP64, and PLCC20 leads exhibited some instances of plating cracks. The SOT3 part was also noted to have some silicon contamination present before cleaning. The distribution of the contamination on the cleaned and re-contaminated part was distributed into the plating grooves and valleys similar to the part before cleaning. ${ }^{16}$ Cross sectioning of the PLCC demonstrated that the Sn plating of the leads is extremely uneven. The XRF measurements reported Sn thicknesses of 8-10 $\mu \mathrm{m}$; however, the actual thicknesses observed during cross sectioning varied from 1 to $38 \mu \mathrm{m}$. Because thin Sn plating is more prone to whisker growth, an $8-\mu \mathrm{m}$ minimum tin plating thickness is recommended for whisker mitigation. ${ }^{1}$

\section{Assembly Characterization}

After soldering, the solder coverage and IMCs were characterized using cross sectioning. A typical cross-section evaluation is shown in Fig. 3. The SOT3 and SOT6 and QFP64 leads were fully covered in solder, but the solder did not always extend to the top of the leads on the SOT5. The QFP44 and PLCC leads were partially covered with solder. The reflowed Sn lead finish beyond the solder no longer exhibited the fine-grain structure of the initial plating. The reflowed Sn and solder grain sizes were typically more than $25 \mu \mathrm{m}$. The thinnest IMC was observed on the alloy- 42 leads $(0.3 \mu \mathrm{m})$. With the alloy-42 leaded parts, the board $(\mathrm{Cu}, \mathrm{Ni})_{6} \mathrm{Sn}_{5} \mathrm{IMC}$ was thicker $(2.6 \mu \mathrm{m})$ than the lead side intermetallic. The SOT3 part was found to have $\mathrm{Cl}$ trapped at the thinnest part of the solder joint between the lead and $\mathrm{Cu}$ pad.

\section{Whisker Characterization After Environmen- tal Testing}

Highlights of the whisker length, growth location, and diameter are presented next. Currently the testing and data analysis are almost finished with the exception of the long term high humidity testing. The vast majority of measurement work was done on SOT boards because similar packages with different thermal coefficient of expansion (CTE) alloys were present. Table I summarizes the subset of whiskers counted and measured on the SOT boards.

The thermal cycling environments promoted whisker growth on the alloy-42 lead terminations, whereas the high-humidity environments caused greater whisker growth on $\mathrm{Cu}$-leaded terminations. The results that follow are for leads that were either grounded or not connected. Preliminary inspection of powered devices indicated that bias did not have a significant impact on whisker growth, but the sample size was small.

\section{PCTC}

Whisker inspections were performed after 250 , $750(250+500)$, and $1750(250+500+1000)$ cycles. No whiskers were observed at the 250 cycle inspection. At the 750 and 1750 cycle inspections, whisker nucleation and growth were observed (Fig. 4). The maximum whisker length was $19.4 \mu \mathrm{m}$ on the SOT3 part with the 1-1 contamination level. Contamination level had a slight impact on whisker length and density. The whiskers grew in the region where the lead exits the solder fillet and the solder is thin (Fig. 5). Although the whiskers in this group were the shortest of all the experiments, it is believed that nucleation and growth would continue with more cycles as was observed in Ref. ${ }^{17}$.

\section{$T C$}

Whisker inspections were performed at 500 and $2110(500+1610)$ cycles. The greatest whisker nucleation and growth occurred from the alloy-42 leads. During thermal cycling, the whisker growth is driven by the CTE differences between the low 
(a)

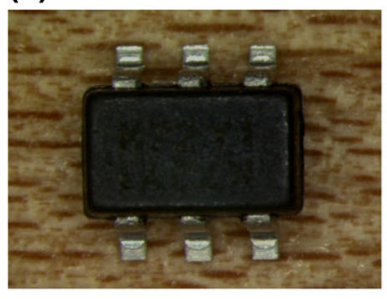

$1 \mathrm{~mm}$

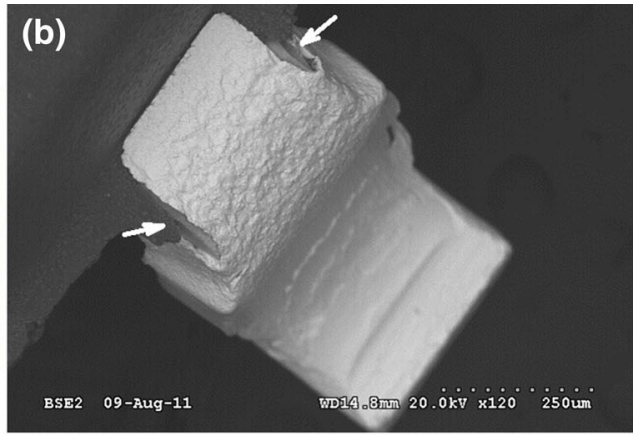

250 um

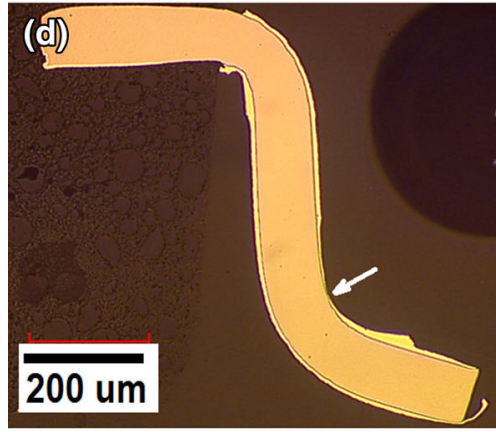

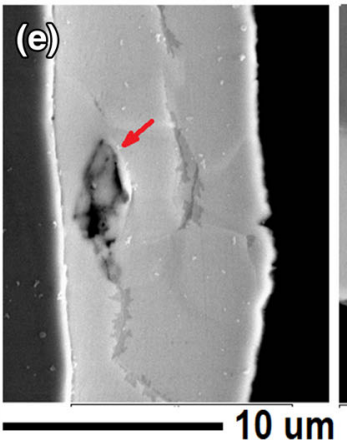

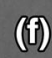

Fig. 2. As-received part lead conditions contributing to whisker growth; (a) SOT6 overall part optical view, (b) SOT5 lead SEM image showing exposed Cu on lead near package body, (c) SOT6 lead SEM image showing exposed alloy-42 base metal near package, (d) SOT6 overall lead optical cross-section view showing thin tin plating caused by lead forming. SEM images of tin plating cross sections show (e) a void within the tin plating, (f) voids and a rough surface, and $(g)$ rough surface with deep grooves.

(a)

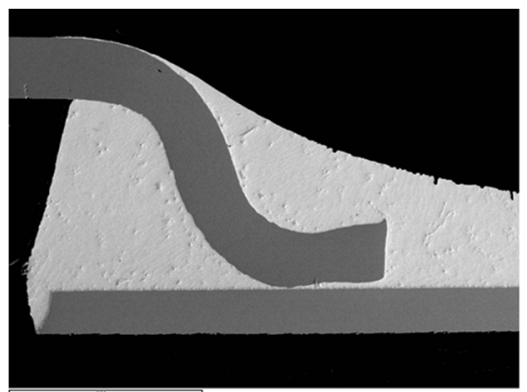

\section{$100 \mathrm{um}$}

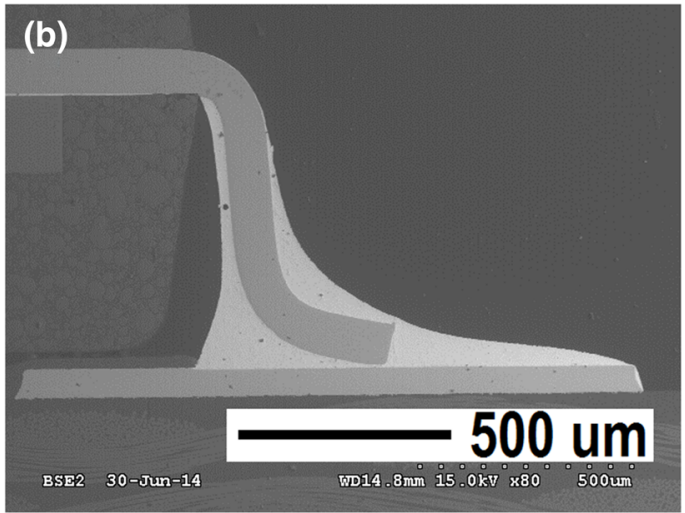

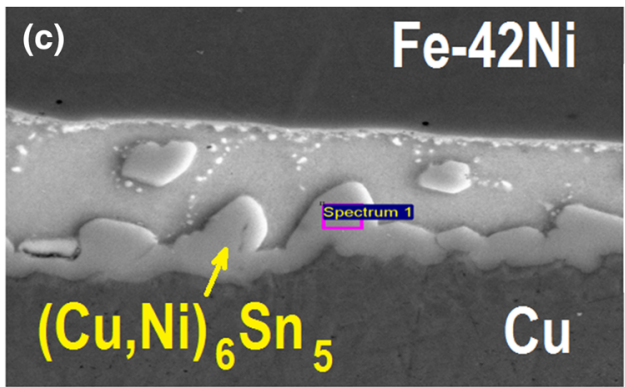

\begin{tabular}{|c|c|c|}
\hline Element & Weight\% & Atomic\% \\
\hline Ni K & 13.37 & 19.81 \\
\hline Cu K & 26.24 & 35.92 \\
\hline Sn L & 60.40 & 44.27 \\
\hline Totals & 100.00 & \\
\hline
\end{tabular}

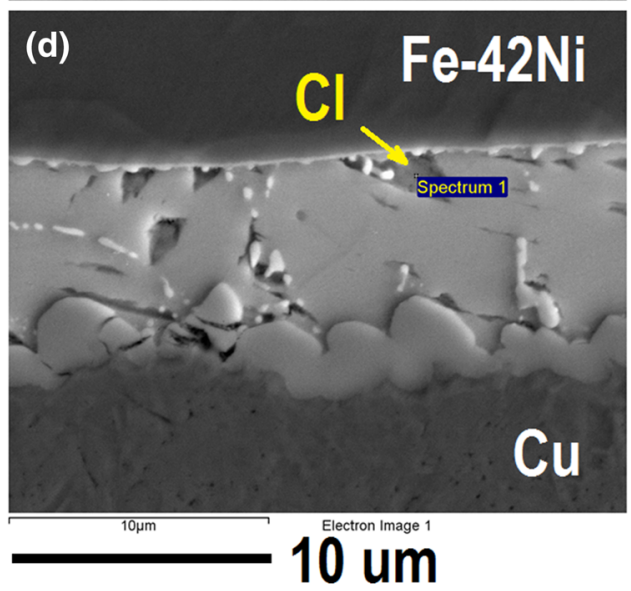

200 um

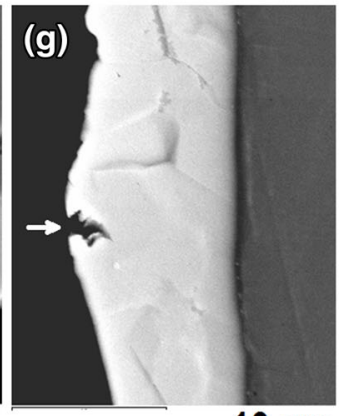

Fig. 3. Alloy 42 leaded SOT solder joint cross-section SEM images after assembly; (a) SOT3 overall, (b) SOT6 overall, (c) $(\mathrm{Cu}, \mathrm{Ni})_{6} \mathrm{Sn}_{5} \mathrm{IMC}$ on board, and (d) Cl contamination trapped in solder joint. 
Table 1. Summary of whisker measurements made on SOT boards

\begin{tabular}{|c|c|c|c|c|}
\hline & Counted & \#Meas. & Counted & \#Meas. \\
\hline Comp. & \multicolumn{2}{|c|}{ PCTC, 1750 cycles } & \multicolumn{2}{|c|}{ HТHН, $1000 \mathrm{~h}$} \\
\hline SOT3 & 216 & 216 & 2438 & 867 \\
\hline SOT6 & 179 & 179 & 1106 & 486 \\
\hline SOT5 & No & No & 12020 & 3388 \\
\hline \multirow{2}{*}{\multicolumn{3}{|c|}{ TC, 2100 cycles }} & \multirow{2}{*}{\multicolumn{2}{|c|}{ HTHH, $4000 \mathrm{~h}$}} \\
\hline & & & & \\
\hline SOT3 & 9130 & 691 & 24639 & 197 \\
\hline SOT6 & 9866 & 1606 & 37641 & 185 \\
\hline SOT5 & 5883 & 63 & 13106 & 107 \\
\hline Total & 24879 & 2360 & 75386 & 489 \\
\hline
\end{tabular}

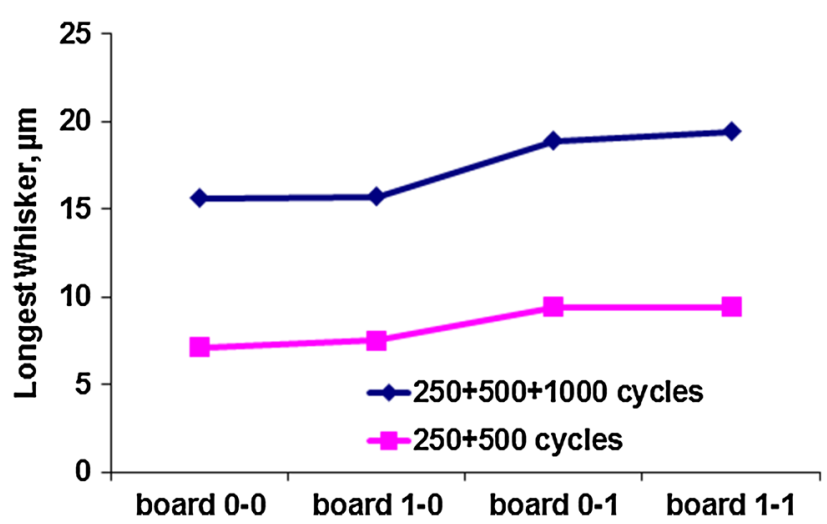

Fig. 4. SOT3 maximum whisker length results after a total of 1750 PCTC cycles.

CTE alloy-42 and the higher CTE solder. The longest whiskers were on the SOT6 termination; $32 \mu \mathrm{m}$ after 500 cycles and $115 \mu \mathrm{m}$ after $2,110(500+1610)$ (Fig. 6). The whiskers on the alloy-42 lead terminations predominantly grew from regions where the solder was thin near the top of the main solder fillet; however, there were also massive tin eruptions indicating a significant amount nonwhisker stress relaxation (Fig. 7).

\section{HTHH}

Whisker inspections were performed at 1000 and $4000(1000+3000)$ cycles. The HTHH environment yielded the longest whisker growth (Fig. 8) when compared with the PCTC and TC environments (note the 3-year LTHH is not yet complete). The HTHH assembly 1000-h exposure resulted in whisker lengths up to $186 \mu \mathrm{m}$, more than three times longer than the 45- $\mu \mathrm{m}$ JESD201 piece part test limit for $4000 \mathrm{~h}\left(55^{\circ} \mathrm{C} / 85 \% \mathrm{RH}\right)$. After $4000 \mathrm{~h}$, the longest whisker was $214 \mu \mathrm{m}$ on the SOT5 solder joints at the $\mathrm{Cu}$ board pad edge. While not part of the main measurement set, the QFP64 terminations also exhibited long tin whisker growth (Fig. 9). The intermediate contamination levels (0-1 and 1-0) exhibited the longest mean whisker length, but the 1-1 contamination grew the longest whiskers. The
$\mathrm{Cu}-\mathrm{Cu}$ (lead-pad) couple exhibited the greatest whisker nucleation and growth (Table I). The alloy$42 / \mathrm{Cu}$ couple exhibited significantly less nucleation and growth after $1000 \mathrm{~h}$ than the $\mathrm{Cu} / \mathrm{Cu}$ couple. However, as the exposure time increased, the whisker length difference was significantly reduced. During HTHH, the whisker growth is driven by oxidation and corrosion (discussed later). Although it is possible that additional contamination accumulated near the board, the cleaned assembly also exhibited significant whisker growth along the board pad edge. The majority of whiskers were between $1 \mu \mathrm{m}$ and $5 \mu \mathrm{m}$ in diameter regardless of alloy or contamination level. After $4000 \mathrm{~h}$, the whisker density varied from 50 to 500 whiskers per termination across the lead material and contamination levels.

There was a marked difference in whisker growth location between the thermal cycling and HTHH. In PCTC, whisker growth was at the top of the solder fillet (Fig. 5) and in TC the whiskers grew from the thin solder on the lead, whereas during HTHH, the majority of whiskers grew from the thin solder regions on the $\mathrm{Cu}$ board pad edge (Fig. 10).

\section{Solder Microstructure and Whiskers}

\section{Recrystallization and Grain Change}

The dynamic recrystallization theory proposed by Vianco and Rejent ${ }^{18,19}$ suggests that there is an optimal stress for whisker growth, above which other nonwhisker growth stress relaxation mechanisms occur. In the current study, varying degrees of recrystallization and stress relaxation were observed. Recrystallized grains adjacent to whiskers have been observed after PCTC and TC (Fig. 11). In some cases, the recrystallization was below the surface (Fig. 12). Possible evidence of recrystallization and/or grain growth was found on the increasing or decreasing whisker diameters observed on the TC samples (Fig. 13). Note that whisker growth angle changes were also observed, which could be due to tin mass transport changes at the whisker base $^{20}$ or grain rotation during cycling. In contrast to observations by Susan et al., ${ }^{20}$ sometimes substantial 

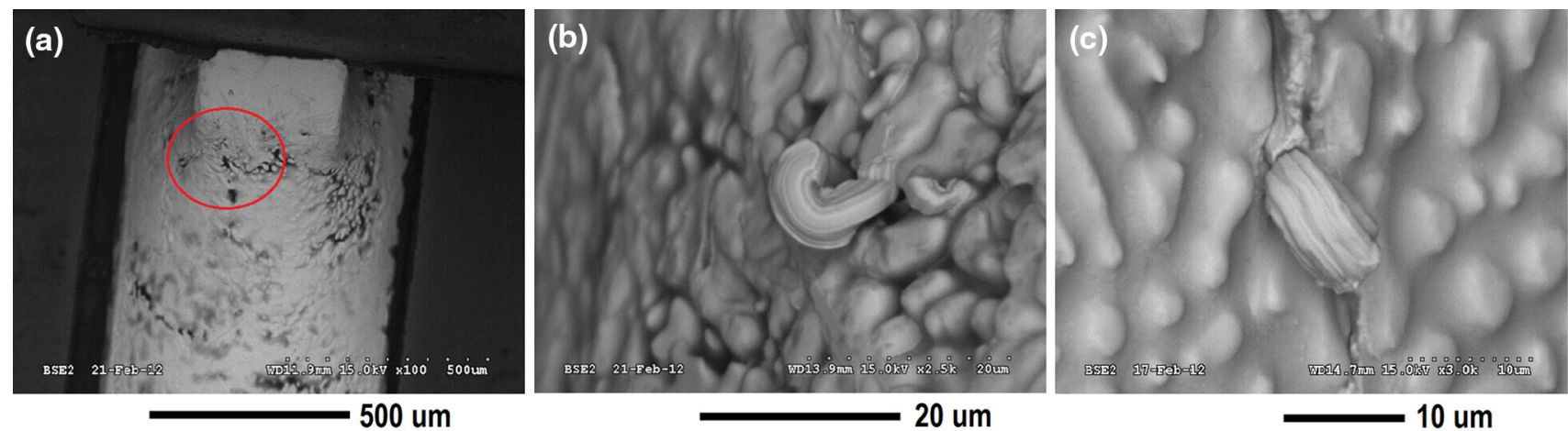

Fig. 5. SEM images showing whisker growth on alloy-42 lead solder joint after a total of 1750 PCTC cycles; (a) and (b) overall views highlighting whisker growth where the lead exits the top of the solder joint with (b) and (c) showing higher magnification whisker growth images.

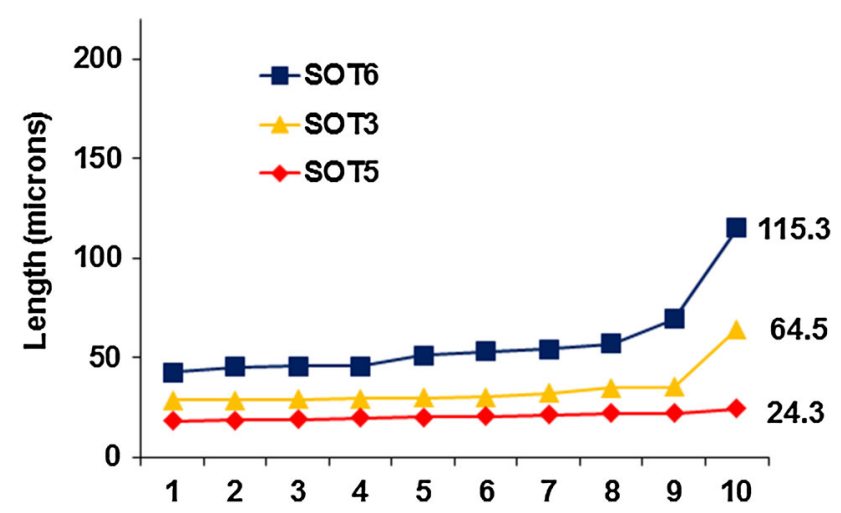

Fig. 6. Top 10 longest whiskers after 2110 TC cycles.

whisker growth occurred after the whisker base diameter increased. The reflowed SAC alloy generally has relatively large tin grains after reflow so recrystallization processes transforming large grains to small grains as part of whisker nucleation and growth are expected.

IMC

Primary IMCs such as $\mathrm{Ag}_{3} \mathrm{Sn}$ and $\mathrm{Cu}_{6} \mathrm{Sn}_{5}$ particles promote whisker nucleation by increasing local stress in temperature cycling through differences in CTE, shear bands, and misoriented deformation zones around hard particles (Fig. 14). The growth of copper-tin IMC between the substrate and tin can also drive whisker growth. ${ }^{3}$ During PCTC, the IMC on lead was observed to grow much faster than expected. The SOT3 IMC before cycling was $0.3 \mu \mathrm{m}$ and after 1,750 PCTC cycles was $1.6 \mu \mathrm{m}-$ more than a five times increase in thickness. In contrast, the IMC on boards before cycling was $2.6 \mu \mathrm{m}$ and after cycling was $3.0 \mu \mathrm{m}$. In addition, large CuNiSn IMCs were observed in the solder fillets next to whiskers. It is postulated that enhanced $\mathrm{Cu}$ diffusion from the board pad to component during cycling promotes IMC formation that increases whisker growth. As will be discussed next, IMCs also contribute to oxidation and corrosion.

\section{Oxidation/Corrosion}

IMC particles contribute to uneven oxidation along the primary Sn grain boundaries, which creates local stress and promotes whisker formation (Fig. 15). The oxidation/corrosion often begins in the Sn interdentric spaces and can penetrate deeply into the solder. The solder fillet region was observed to be partially oxidized during the HTHH exposure with some oxide/corrosion regions traversing the entire solder fillet thickness to the substrate (Fig. 16). When all the tin around the whisker base becomes oxidized/corroded, whisker will stop growing. In addition, as oxidation/corrosion proceeds, whisker ductility is reduced and it is easier for the whiskers to become detached from the substrate. Corrosion was also observed adjacent to a whisker after the very low-humidity PCTC environment. The compressive stress caused by the $29-34 \%$ volume increase of the Sn oxides compared with the $\beta$ Sn promotes whisker growth. These findings are consistent with other investigators assessing the role of humidity on tin whisker growth on electronic component leads ${ }^{21-23}$ and on lead-free assemblies. ${ }^{5}$

It is important when studying whisker growth of solder joints that all the material interaction be considered. In alloy- 42 solder joints, $\mathrm{Cu}_{6} \mathrm{Sn}_{5}$ interfacial layer at the board pads and solder particles contain $\mathrm{Ni}$, which reduces the galvanic potential between the IMCs and the Sn, slowing the oxidation rate and the accompanying whisker nucleation. $\mathrm{Ni}$ from alloy-42 retarded whisker nucleation from the board $\mathrm{Cu}$ pads (Fig. 17). This is due to the $\mathrm{Ni}$ in the alloy-42 promoting the formation of the $(\mathrm{CuNi})_{6} \mathrm{Sn}_{5}$ ternary IMC on the board $\mathrm{Cu}$ pad.

Surface roughness of the solder also contributes to corrosion-induced whiskering. The roughness is 


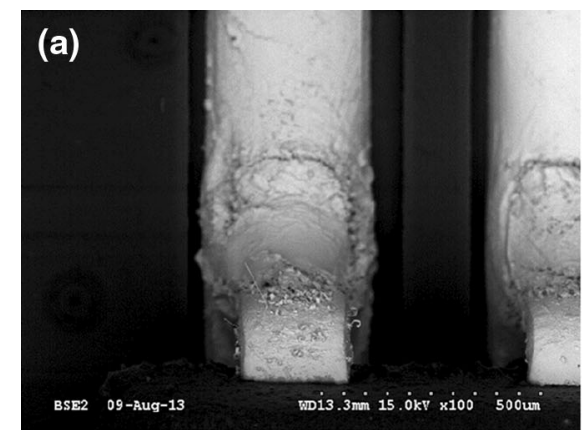

500 um

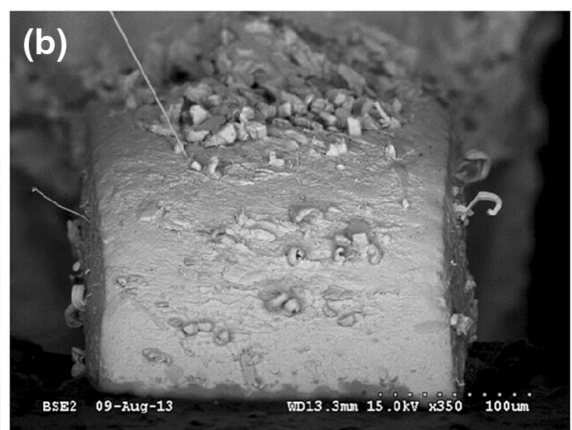

100 um

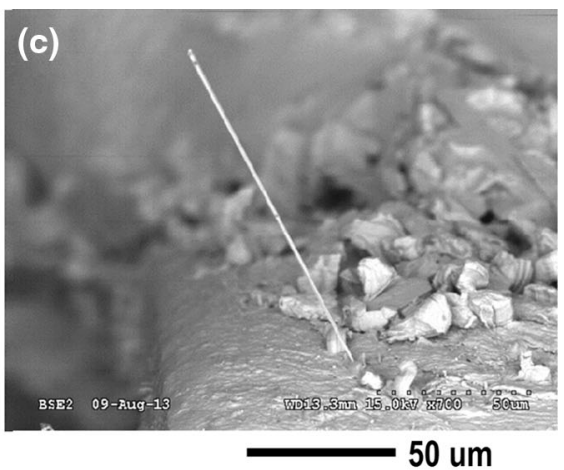

50 um

Fig. 7. SEM images showing whiskers growing from alloy-42 lead after 2110 TC cycles; (a) overall of lead with (b) and (c) showing whisker region at increasing magnifications.
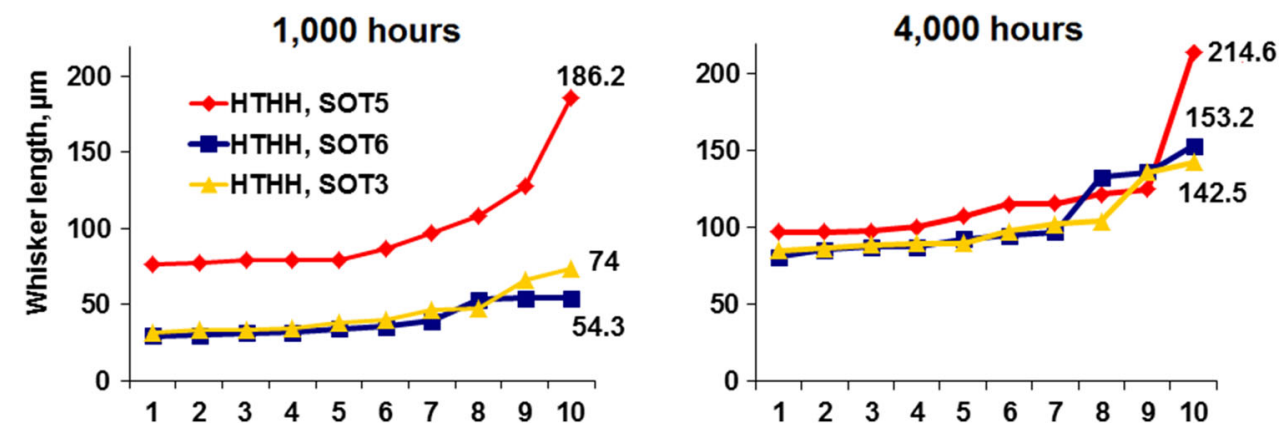

Fig. 8. Comparison of top 10 longest whiskers after 1000 and $4000 \mathrm{HTHH}$ hours.

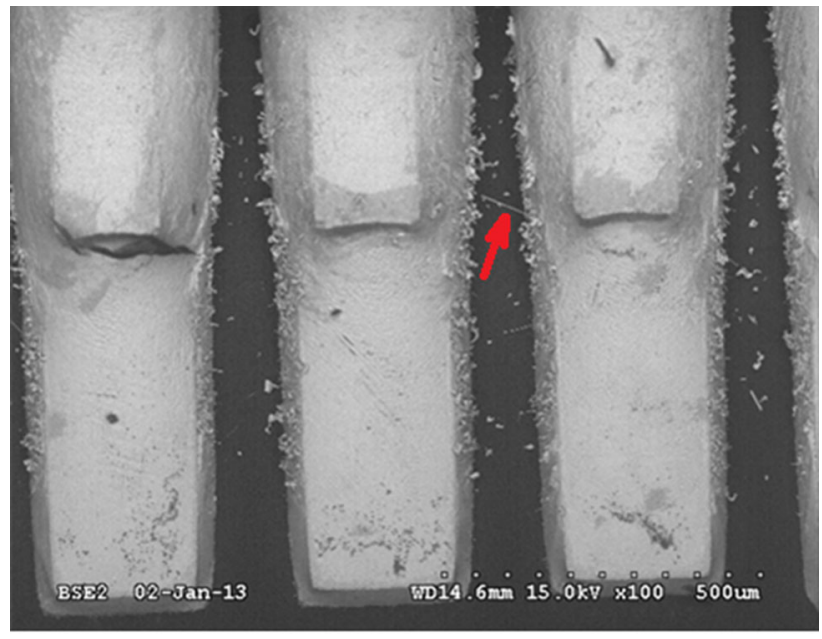

500 um

Fig. 9. SEM image showing whisker growth from QFP64 board pads after $4000 \mathrm{HTHH}$ hours.

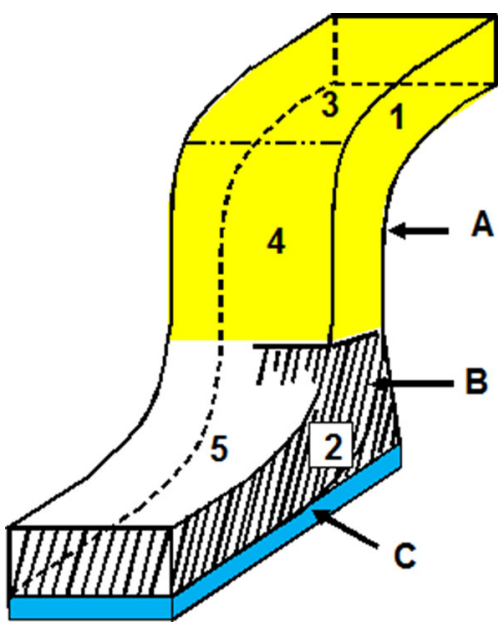

Fig. 10. Primary whisker growth regions after TC and HTHH environments. The thin solder in region A exhibited the majority of the whisker growth after TC of alloy-42 lead terminations. The thick solder in region $\mathrm{B}$ displayed little or no whisker growth. The thin solder over the copper board pad in region $\mathrm{C}$ produced the most whisker growth after $\mathrm{HTHH}$. 

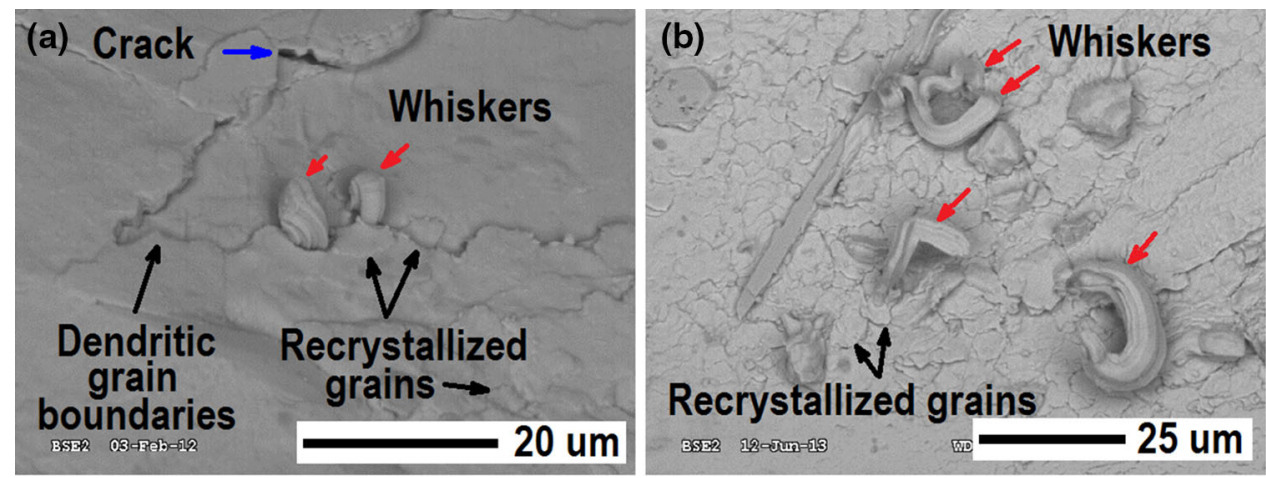

Fig. 11. SEM image showing whisker growth near recrystallized grains and dendritic grain boundaries on the SAC solder fillets after (a) 1750 PCTC cycles and (b) 2110 TC cycles.
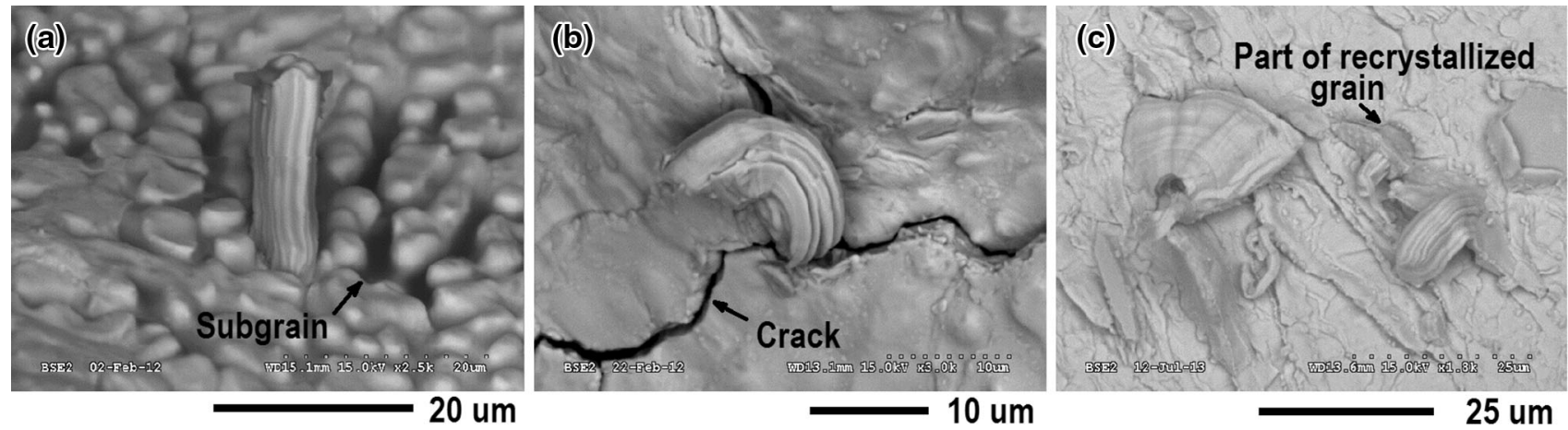

Fig. 12. Subsurface grain recrystallization: (a) from subgrain region after 1750 PCTC cycles and (b) from primary tin dendrite triple junction after 1750 PCTC cycles. (c) A whisker on top of an underlying recrystallized grain after 2110 TC cycles.
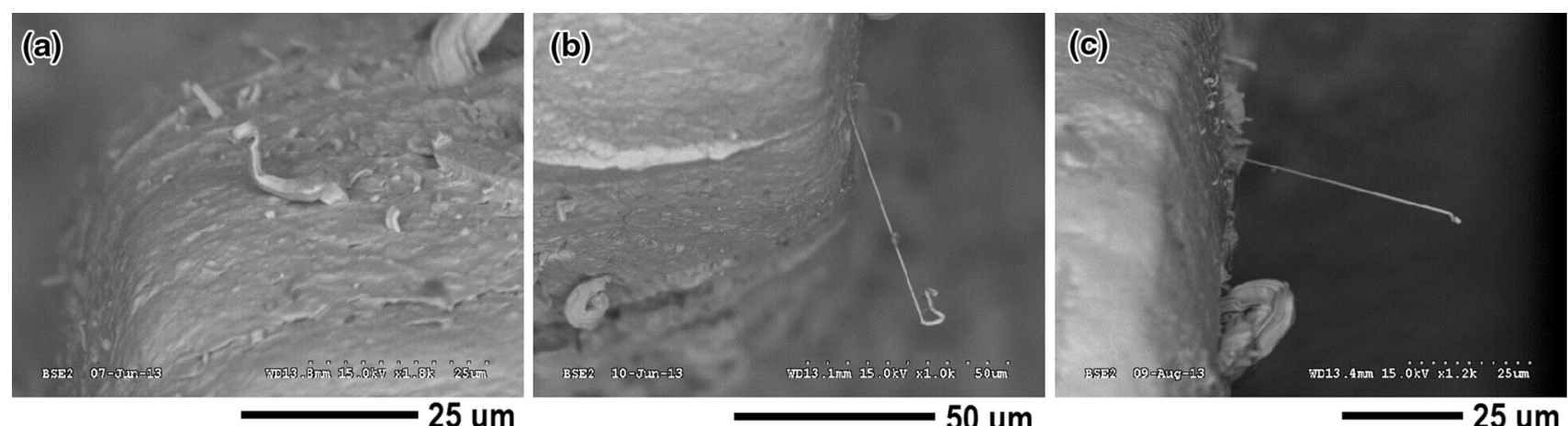

Fig. 13. SEM image showing whisker diameter change during TC exposure on alloy-42 SOT6 with 1-0 contamination; (a) increasing, (b) and (c) decreasing whisker diameters.

partly a result of the shrinkage of the liquid between the primary tin dendrites. The roughness tends to trap contamination, which is difficult to clean (Fig. 12a).

\section{Broken Whiskers}

There are two possible explanations for the large amount of broken whiskers found during the 

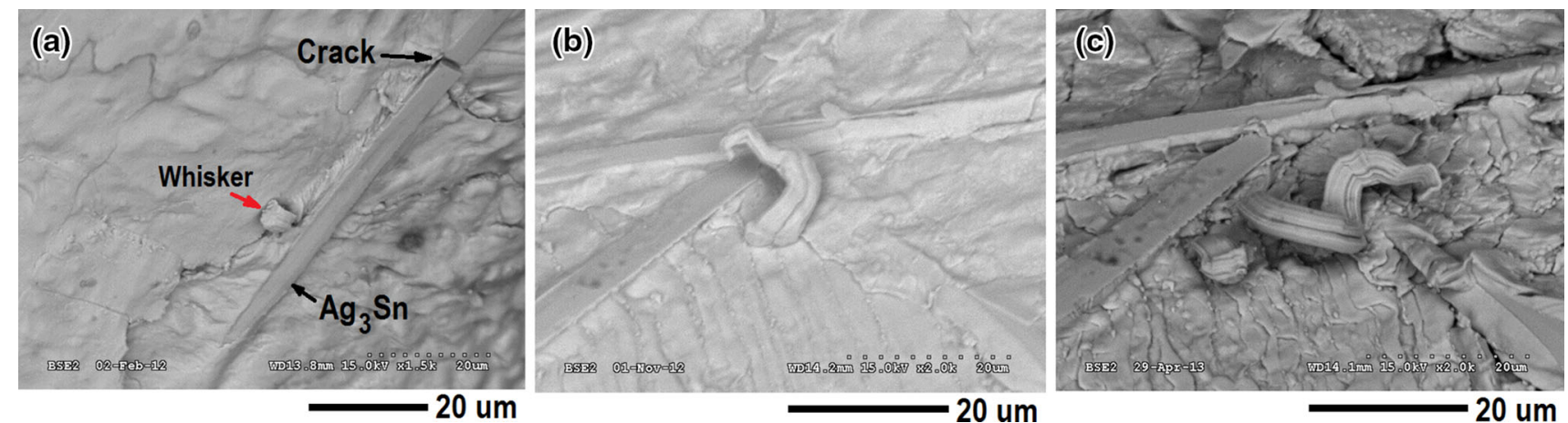

Fig. 14. SEM image showing whisker on alloy-42 lead adjacent to $\mathrm{Ag}_{3} \mathrm{Sn} I \mathrm{IMC}$ plate: (a) after 1750 PCTC cycles and (b) after $500 \mathrm{TC}$ cycles. (c) Continued growth of whisker in (b) and new whisker growth after 2110 TC cycles.
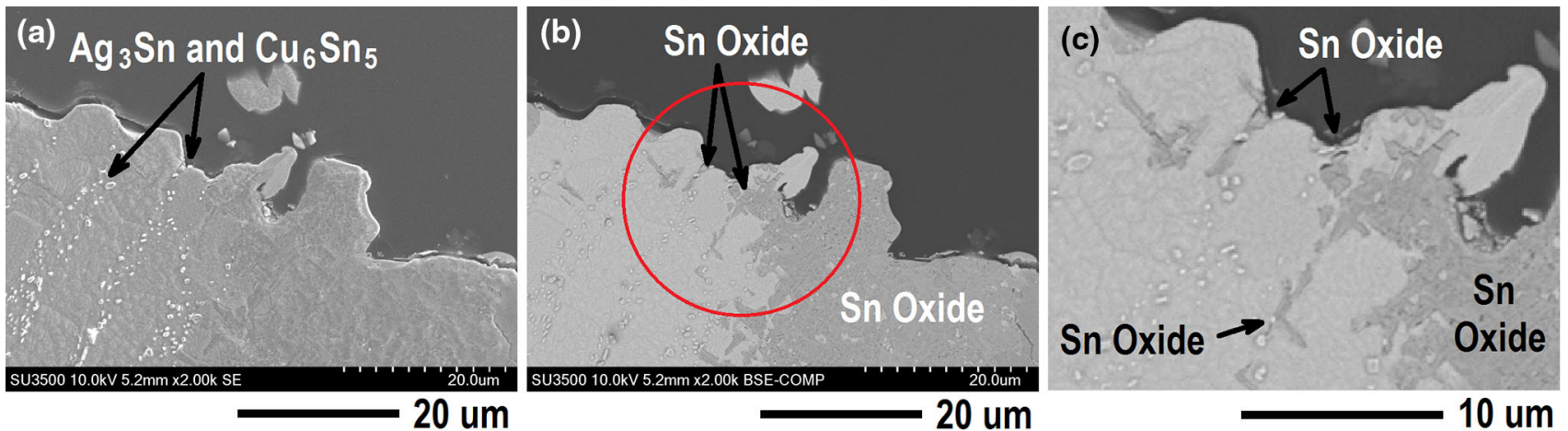

Fig. 15. Cross section showing uneven Sn oxidation into the IMC region between the primary Sn grain boundaries: (a) secondary electron SEM image highlighting the IMC with (b) and (c) backscatter SEM images emphasizing the Sn oxide penetration into the solder. Image (c) is a higher magnification view of the circled area in (b).

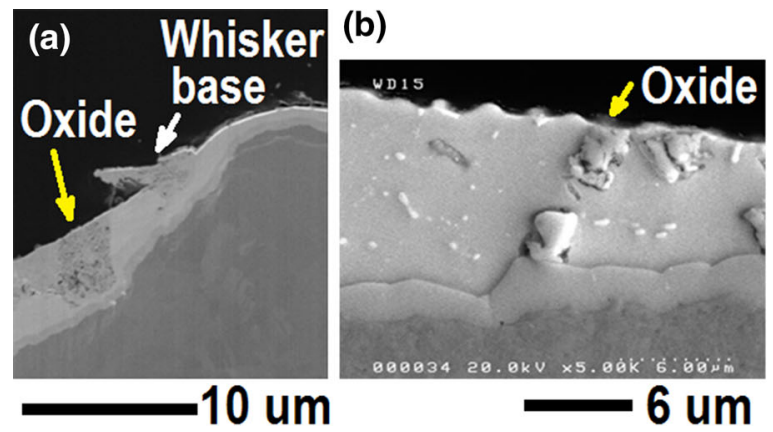

(c)

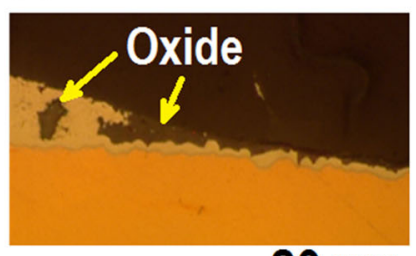

20 um (d)

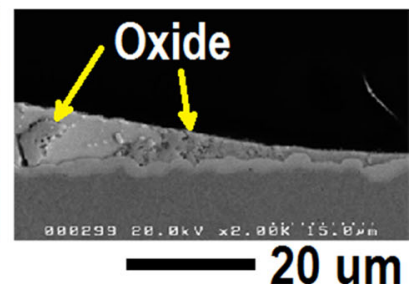

Fig. 16. Cross section showing partial oxidation of SAC solder with Cu leaded part (SOT5) and 1-1 contamination after $4000 \mathrm{~h}$ HTHH: (a) SEM image of oxide near 98- $\mu \mathrm{m}$ long whisker, (b) SEM image of oxide in a thicker region of the SAC solder, (c) optical image of oxidation near solder wetting line, and (d) SEM image of region shown in (c).

examination at $4000 \mathrm{HTHH}$ hours. Some of the thin regions of solder were completely oxidized and had no whiskers on the surface (Fig. 16). This finding suggests that oxidation/corrosion propagating un- der a whisker can make the whisker attachment to the base more brittle. In another cross-section of a whisker through its base, voids and a crack were observed (Fig. 18). 


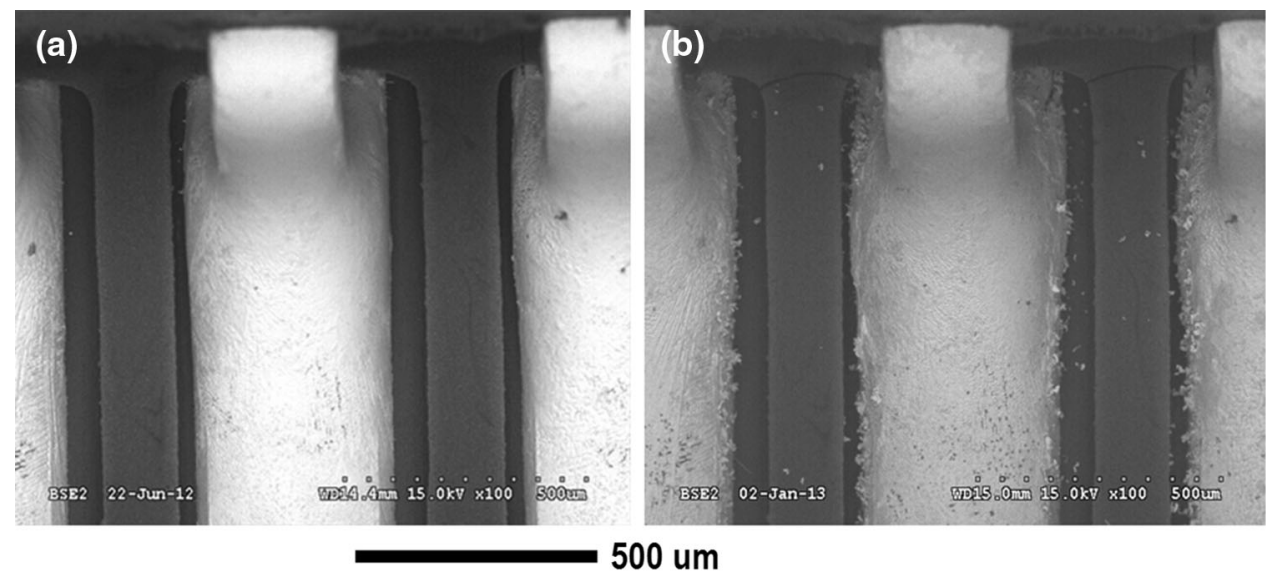

Fig. 17. SEM image showing board Cu pad region whisker nucleation inhibition due to alloy-42 lead material: (a) $1000 \mathrm{~h}$ and (b) $4000 \mathrm{~h}$ of $\mathrm{HTHH}$.

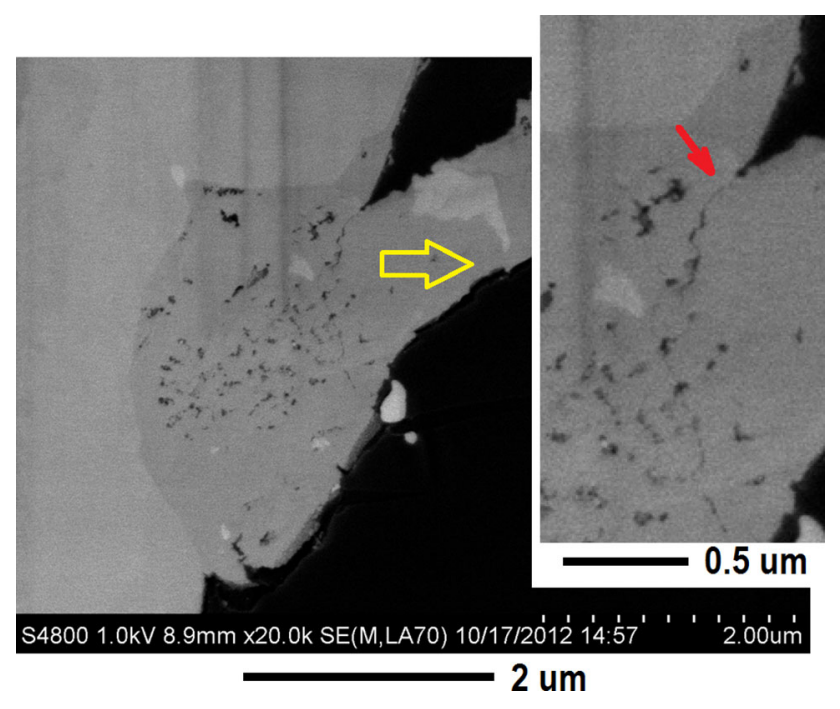

Fig. 18. SEM image showing voids and cracks observed in the whisker base after $4000 \mathrm{HTHH}$ hours.

\section{Nonwhisker Growth Stress Relaxation}

In some cases, nonwhisker growth stress relaxation occurred. During PCTC in the thicker solder region, faceted crystal growth was observed (Fig. 19). Under the higher stress conditions of TC, the alloy-42 solder joints eventually exhibited massive cracking (Fig. 20) and massive eruptions consisting of many recrystallized grains (Fig. 7).

\section{Test Considerations}

An important test observation was that the intermediate SEM inspections stopped some whiskers from further growth after resuming environmental exposure. This condition was most pronounced on the HTHH samples where the majority of whiskers inspected at $1000 \mathrm{~h}$ stopped growing further when inspected at $4000 \mathrm{~h}$, but new whiskers formed (Fig. 21). The interruption of whisker growth by inspection during thermal
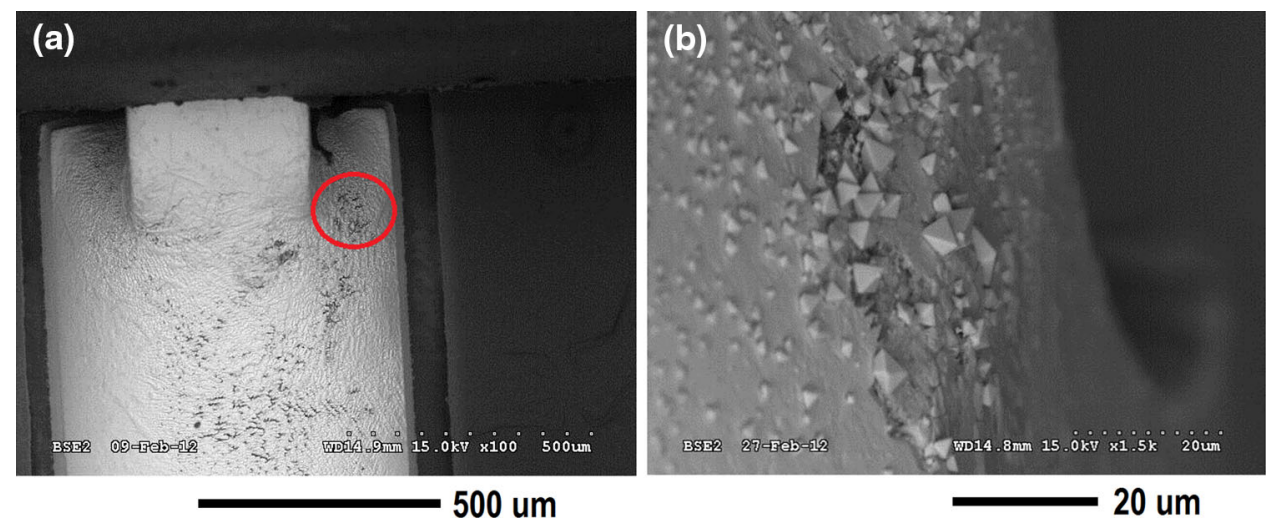

Fig. 19. SEM image showing faceted grains on alloy-42 SOT3 with 1-1 contamination after 1750 PCTC cycles: (a) overall view and (b) high magnification view of circled region in (a). 
cycling (TC or PCTC) was less pronounced and existing whiskers continued to grow (Fig. 14). Thus, periodic inspection will cause an underreporting of

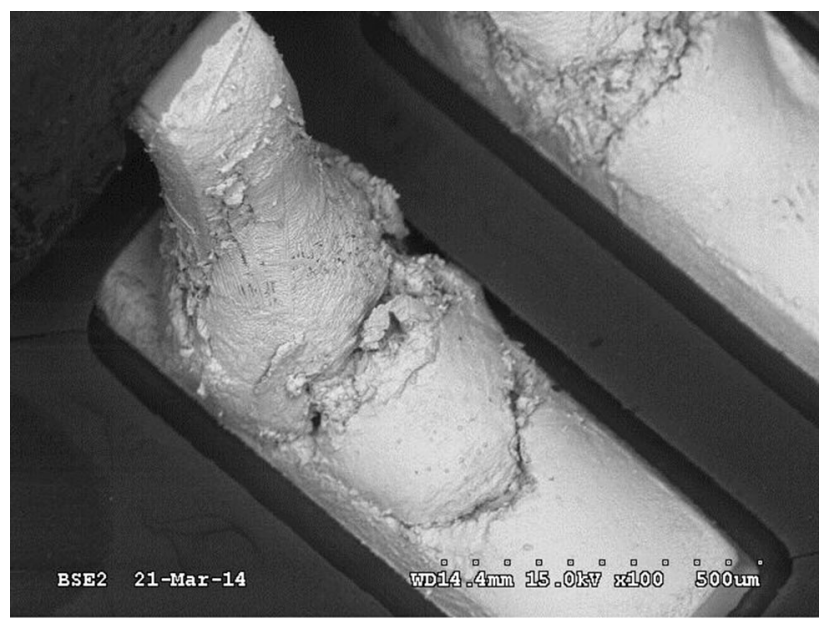

500 um

Fig. 20. SEM image showing an alloy-42 termination solder joint with massive cracking after 2110 TC cycles. whisker length. By progressively increasing time intervals or having longer uninterrupted tests, longer whisker growth would be obtained.

\section{REE Oxidation}

The SAC solder with REE was included in the test matrix because REE additions have increased the SAC solder whisker growth propensity. ${ }^{24,25}$ Ce was chosen over $\mathrm{La}$ and $\mathrm{Y}$ because results have been published indicating that Ce has better oxidation resistance, ${ }^{25}$ which would be promising for incorporation in lead-free solder. The preliminary experiment in the current work ${ }^{26}$ had a different result; Ce was at least as effective as $\mathrm{Y}$ and La in whisker formation. Therefore, to discourage industry from even considering Ce additions to electronic solder, the BGA board used $\mathrm{Ce}$ at a concentration much lower than the $2 \%$ being considered for improving drop shock performance and whisker growth was still observed (Fig. 22). The manner in which RESn compound oxidation contributes to whisker growth is (I) liberation of Sn and (II) development of compressive stress by the RE oxide. Because REEs are less noble than Sn, RE in $\mathrm{RESn}_{3}$ is more prone to oxidation, which results in
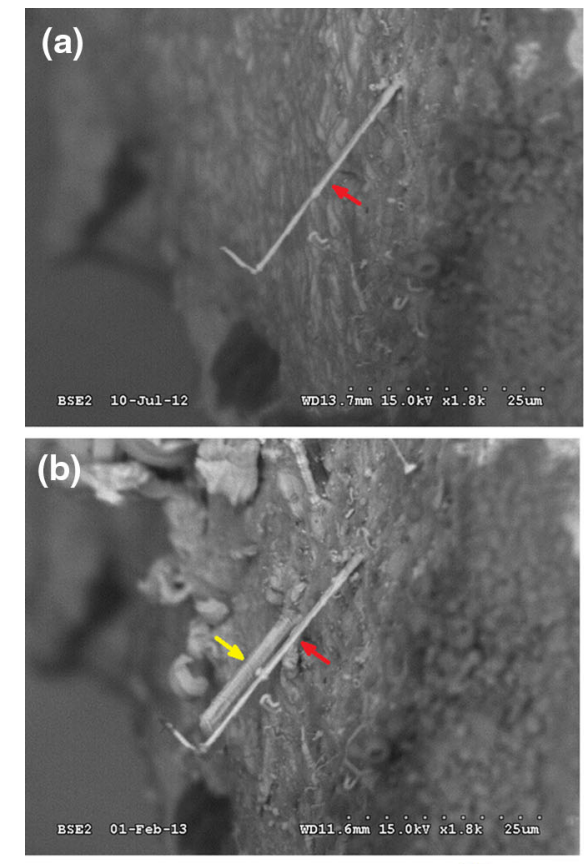

25 um
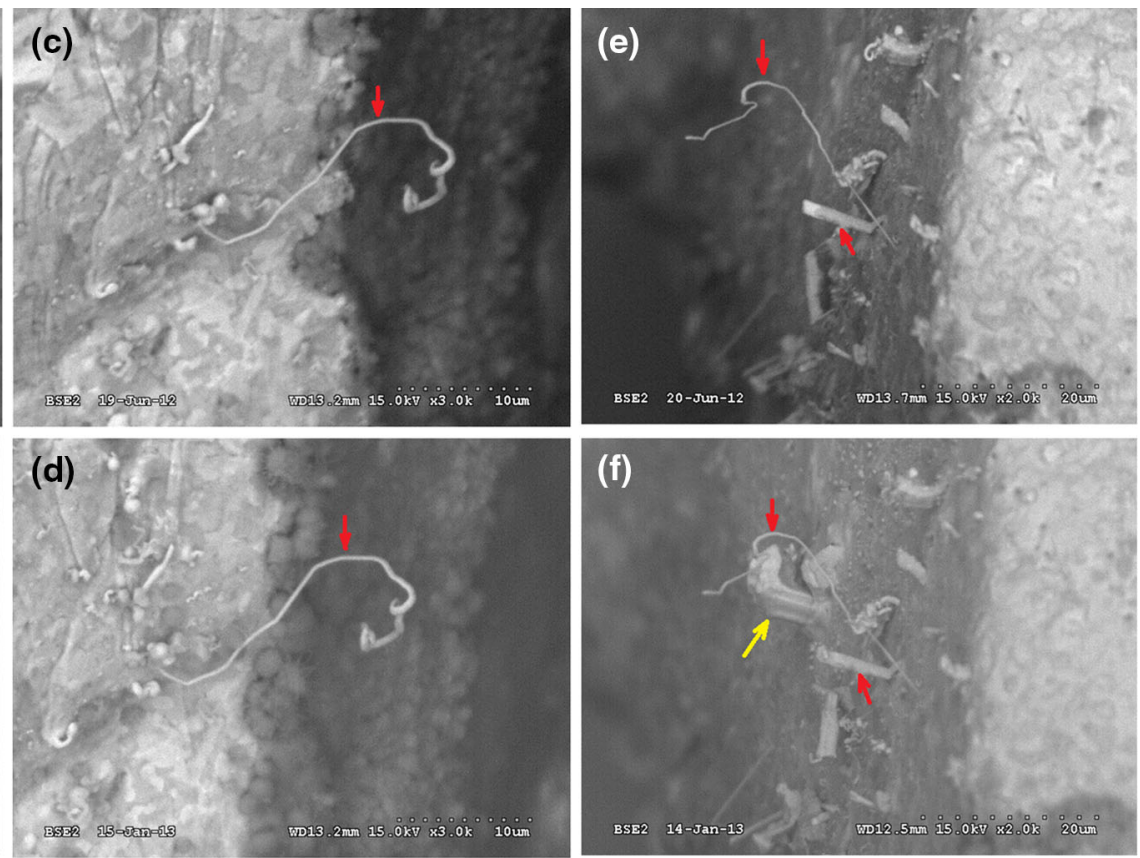

10 um

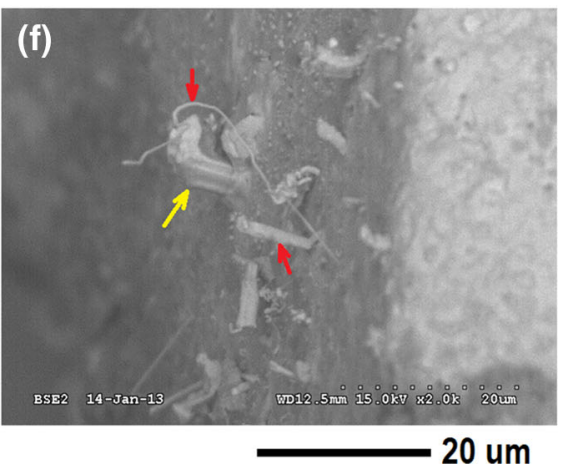

Fig. 21. SEM images showing whisker growth interruption by the inspection process during HTHH testing. Red arrows indicate whiskers that stopped growing and yellow arrows indicate new whisker growth: (a) SOT5 1-0, U26, lead 1, $1000 \mathrm{~h}$; (b) SOT5 1-0, U26, lead 1, $4000 \mathrm{~h}$; (c) SOT5 1-1, U37, lead 5, 1000 h; (d) SOT5 1-1, U37, lead 5, 4000 h; (e) SOT5 1-1, U38, lead 2, 1000 h; and (f) SOT5 1-1, U38, lead 2, 4000 h. 

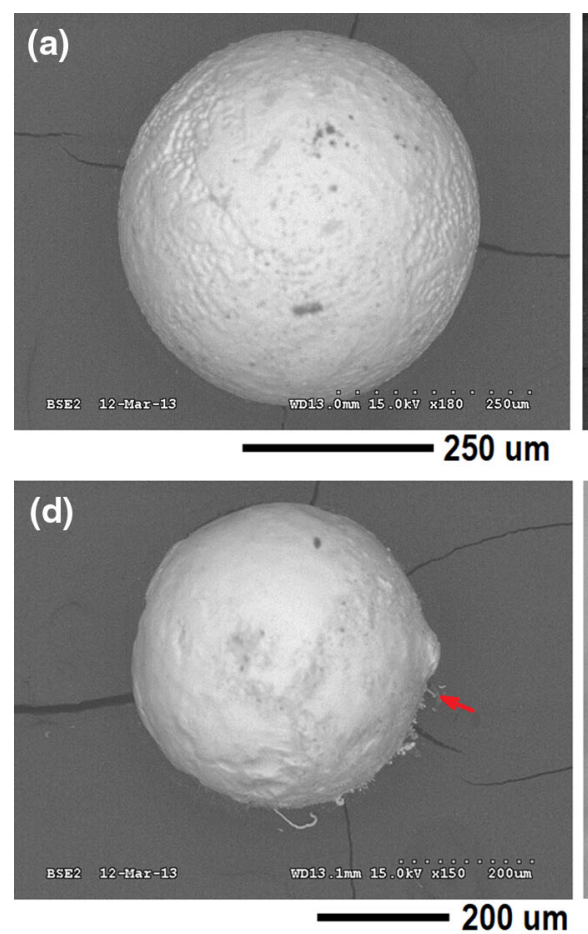

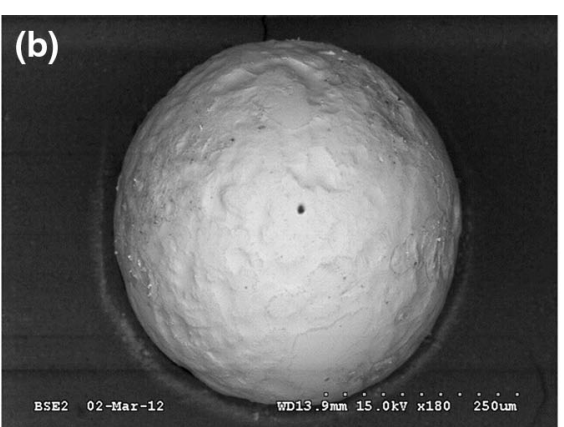

250 um

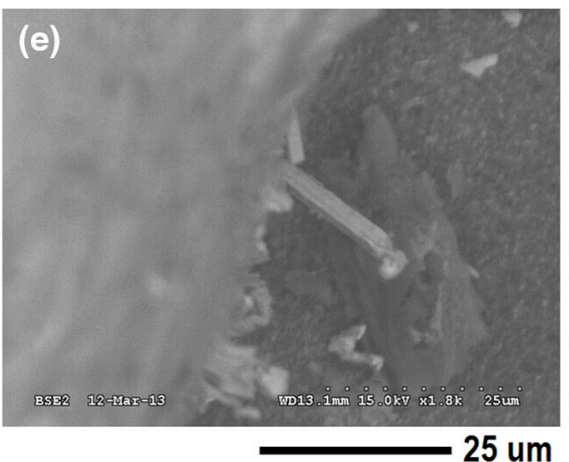

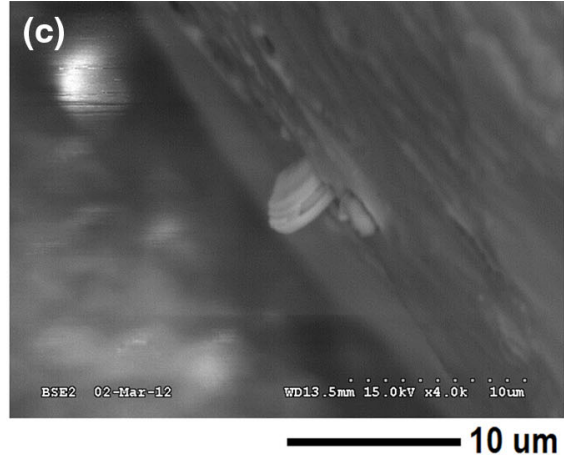

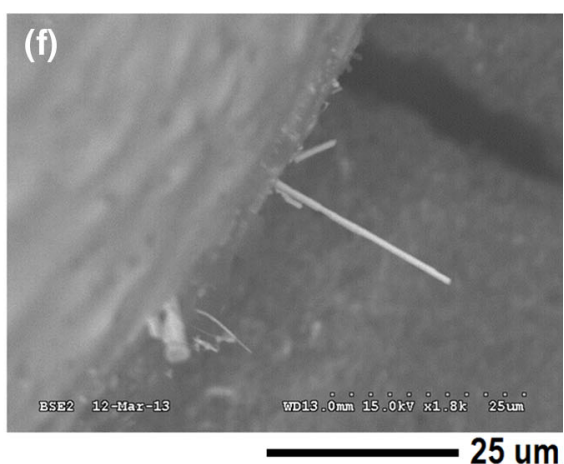

Fig. 22. SEM images comparing SAC105 (a) with SAC105 + 0.01Ce (b-f) solder balls attached to BGA board pads with SAC305 solder paste after $4000 \mathrm{HTHH}$ hours (a, $d-f)$ and after 1,750 PCTC cycles (b and c) at a 0-0 contamination level; (a) highlights no whisker growth on a SAC105 ball. Image (e) shows whisker highlighted by arrow in (d).

rapid oxidation of $\mathrm{CeSn}_{3}$ (or $\mathrm{YSn}_{3}$ and $\mathrm{LaSn}_{3}$ ). In addition, the surface active nature of REEs results in a condition where RESn IMC tends to segregate to the surface giving it improved access to oxygen. RESn IMCs can also be exposed to air if cracks form during solder joint thermal cycling.

\section{CONCLUSION}

Based on a systematic study of electronic assemblies with leaded components covered with SAC305 solder, the following conclusions can be made. Whiskers grow from solder fillets around component leads and $\mathrm{Cu}$ pads, particularly where the solder is less than $25 \mu \mathrm{m}$ thick. Very long whiskers can grow from SAC305 fillets. Whisker risks must be considered for high-reliability equipment. Thermal cycling promotes whisker growth when tin is on low CTE base materials. The stresses in the mild $+50^{\circ} \mathrm{C}$ to $+85^{\circ} \mathrm{C}$ PCTC cycle were sufficient to initiate recrystallization of the lead-free solder and nucleation of whiskers. Even though the $-55^{\circ} \mathrm{C}$ to $85^{\circ} \mathrm{C}$ cycling does not create optimal stress conditions for whisker growth from alloy-42 terminations in SAC305 assembly, the alloy-42 leads still exhibited whisker lengths longer than the JESD201 piece part test limits. High humidity promotes whisker growth when thin SAC is on $\mathrm{Cu}$. The $85^{\circ} \mathrm{C} / 85 \mathrm{RH} 1,000-\mathrm{h}$ exposure on an assembly resulted in whisker lengths longer than the JESD201 piece part test limits for $4000 \mathrm{~h}$. All the solder joint materials are important for ascertaining whisker growth. Although Ni tended to retard nucleation on $\mathrm{Cu}$ pads in $\mathrm{HTHH}$, it tended to promote whisker growth by forming thick CuNiSn IMC on alloy-42 leads during PCTC. Assembly contamination is an important consideration for whisker growth in harsh service environments. REE additions to lead-free solder significantly increase whisker growth. Last, interruption of high-humidity conditions during interim inspections can cause an underreporting of whisker length.

\section{ACKNOWLEDGEMENTS}

The work was performed under the Strategic Environmental Research and Development Programs, a partnership between the U.S. Department of Defense, Environmental Protection Agency, and the Department of Energy, Project WP1753. The authors would like to thank the following individuals from Celestica: David Yang and Andre Delhaise for whisker SEM inspections and analysis, Russell Brush and Alon Walk for ATC testing and data analysis, Andrea Rawana for DSC analysis, and the following people from BAE Systems: Stephen McKeown, Clive Morris, Craig Sabin, and John Dion for their help with the tin whisker evaluation plan, and Don Hewett for his help with the test vehicle design.

\section{OPEN ACCESS}

This article is distributed under the terms of the Creative Commons Attribution License which permits any use, distribution, and reproduction in any medium, provided the original author(s) and the source are credited. 


\section{REFERENCES}

1. GEIA-STD-0005-2, Standard for Mitigating the Effects of Tin Whiskers in Aerospace and High Performance Electronic Systems (Warrendale, PA: SAE Int., 2012).

2. G.T. Galyon, IEEE Trans. Electron. Packag. Manuf. 28, 94 (2005).

3. K.N. Tu, Phys. Rev. B 49, 2030 (1994).

4. M. Dittes, P. Oberndorff, P. Crema, and V. Schroeder, IEEE Proceedings of the Electronic Package Technology Conference (Piscataway, NJ: IEEE, 2003), pp. 822-826.

5. J.W. Osenbach, R.L. Shook, B.T. Vaccaro, B.D. Potteiger, A.N. Amin, K.N. Hooghan, P. Suratkar, and P. Ruengsinsub, IEEE Trans. Electron. Packag. Manuf. 28, 36 (2005).

6. F. Pei, N. Jadhav, and E. Chason, Appl. Phys. Lett. 100, $221902(2012)$.

7. W.J. Boettinger, C.E. Johnson, L.A. Bendersky, K.-W. Moon, M.E. Williams, and G.R. Stafford, Acta Mater. 53, 5033 (2005).

8. E.R. Crandall, G.T. Flowers, P. Lall, and M.J. Bozack, Proceedings of the 57th IEEE Holm Conference Electronic Contacts (Piscataway, NJ: IEEE, 2011), pp. 1-5.

9. P. Sarobol, Y. Wang, W.H. Chen, A.E. Pedigo, J.P. Koppes, J.E. Blendell, and C.A. Handwerker, JOM 65, 1350 (2013).

10. T. Woodrow, Proceedings of the Surface Mount Technologies Association International Conference (Edina, MN: SMTA, 2006), pp. 674-723.

11. T. Fang, M. Osterman, and M. Pecht, Microelectron. Reliab. 46, 846 (2006).

12. L. Panashchenko and M. Osterman, Proceedings of the 59th IEEE Electronic Components Technology Conference (Piscataway, NJ: IEEE, 2009), pp. 1037-1043.
13. A. Baated, K.S. Kim, K. Suganuma, S. Huang, B. Jurcik, S. Nozawa, and M. Ueshima, J. Mater. Sci. 21, 1066 (2010).

14. K. Sweatman, J. Masuda, T. Nozu, M. Koshi, and T. Nishimura, Proceedings of the 2010 Technology Conference IPC APEX EXPO (Bannockburn, IL: IPC, 2010), pp. S11_021-S11_02-5.

15. S. Meschter, S. McKeown, P. Snugovsky, and J. Kennedy, SMTA J. 24, 23 (2011).

16. P. Snugovsky, S. Meschter, Z. Bagheri, E. Kosiba, M. Romansky, and J. Kennedy, J. Electron. Mater. 41, 204 (2012).

17. P. Snugovsky, Z. Bagheri, and M. Romansky, SMTA International Conference Soldering and Reliability (Edina, MN: SMTA, 2008).

18. P.T. Vianco and J.A. Rejent, J. Electron. Mater. 38, 1815 (2009).

19. P.T. Vianco and J.A. Rejent, J. Electron. Mater. 38, 1826 (2009).

20. D. Susan, J. Michael, R.P. Grant, B. McKenzie, and W.G. Yelton, Metall. Mater. Trans. A 44, 1485 (2013).

21. J.W. Osenbach, J.M. DeLucca, B.D. Potteiger, A. Amin, R.L. Shook, and F.A. Baiocchi, IEEE Trans. Electron. Packag. Manuf. 30, 23 (2007).

22. P. Oberndorff, M. Dittes, P. Crema, P. Su, and E. Yu, IEEE Trans. Electron. Packag. Manuf. 29, 239 (2006).

23. P. Su, J. Howell, and S. Chopin, IEEE Trans. Electron. Packag. Manuf. 29, 246 (2006)

24. T.-H. Chuang and S.-F. Yen, J. Electron. Mater. 35, 1261 (2006).

25. M.A. Dudek and N. Chawla, J. Electron. Mater. 38, 210 (2009).

26. D. Perovic, L. Snugovsky, J. Rutter, P. Snugovsky, Z Bagheri, and S. Meschter, SMTA Interantional Conference Soldering and Reliability (Edina, MN: SMTA, 2011). 